\title{
EULAR recommendations for vaccination in paediatric patients with rheumatic diseases
}

\author{
M W Heijstek, ${ }^{1}$ L M Ott de Bruin, ${ }^{1}$ M Bijl, ${ }^{2}$ R Borrow, ${ }^{3,4}$ F van der Klis, ${ }^{5}$ I Koné-Paut, ${ }^{6}$ \\ A Fasth, ${ }^{7} \mathrm{~K}$ Minden, ${ }^{8}$ A Ravelli, ${ }^{9} \mathrm{M}$ Abinun, ${ }^{10} \mathrm{G}$ S Pileggi, ${ }^{11} \mathrm{M}$ Borte, ${ }^{12} \mathrm{~N}$ M Wulffraat ${ }^{1}$
}

- Additional supplementary tables are published online only. To view these files please visit the journal online (http://ard. bmj.com).

For numbered affiliations see end of article

\section{Correspondence to}

Dr M W Heijstek, Department of Paediatric Immunology, Wilhelmina Children's Hospital, University Medical Centre Utrecht, Room KC 03.063.0, P0 Box 85090, 3508 AB Utrecht, The Netherlands; m.w.heijstek@umcutrecht.nl

Accepted 11 June 2011 Published Online First 3 August 2011

\section{ABSTRACT}

Evidence-based recommendations for vaccination of paediatric patients with rheumatic diseases (PaedRD) were developed by following the EULAR standardised procedures for guideline development. The EULAR task force consisted of (paediatric) rheumatologists/immunologists, one expert in vaccine evaluation, one expert in public health and infectious disease control, and one epidemiologist. A systematic literature review was conducted in MEDLINE, EMBASE, and abstracts of the EULAR and American College of Rheumatology meetings of 2008/9. The level of evidence and strength of recommendation were based on customary scoring systems. Delphi voting was applied to assess the level of agreement between task force members. 107 papers and eight abstracts were used. The majority of papers considered seasonal influenza (41) or pneumococcal (23) vaccination. 26 studies were performed specifically in paediatric patients, and the majority in adult rheumatoid arthritis and systemic lupus erythematosus patients. Fifteen recommendations were developed with an overall agreement of $91.7 \%$. More research is needed on the safety and immunogenicity of (live-attenuated) vaccination in PaedRD, particularly in those using biologicals, and the effect of vaccination on prevention of infections.

Vaccination has greatly reduced the burden of childhood infections. ${ }^{1}$ Paediatric patients with rheumatic diseases (PaedRD) are at increased risk of infections, due to the immunosuppressive effect of the disease or its treatment. ${ }^{2-4}$ With current aggressive treatment strategies incorporating the early use of immunosuppressive drugs and biological agents, susceptibility to infections increases further. ${ }^{5}$ In this context, safe vaccination and adequate serological responses to vaccinations are vital. The immunogenicity of vaccinations might be reduced as a result of the immunosuppressed status. In addition, the safety profile might differ from healthy subjects. Moreover, the potential effects of vaccination on the underlying disease must be considered. Generally, recommendations on the immunisation of children with rheumatological diseases follow the recommendations for immunosuppressed patients (patients with solid organ transplantation, haematological malignancy, immunodeficiency), in which live-attenuated vaccines are contraindicated when using high-dose immunosuppressive drugs. ${ }^{6} 7$ However, to what extent antirheumatic treatment actually suppresses the immune system remains unclear.

Our aim was to develop recommendations for vaccinations in PaedRD based on available evidence in the literature.

\section{METHODS}

The recommendations were constructed using the European League Against Rheumatism (EULAR) standard operating procedures. ${ }^{8}$ An expert committee was instituted, consisting of eight paediatric rheumatologists/immunologist (IK-P, AF, $\mathrm{KM}, \mathrm{AR}, \mathrm{MA}, \mathrm{GSP}, \mathrm{MB}, \mathrm{NMW})$, one adult rheumatologist/immunologist (MB), one expert in vaccine evaluation (RB), one expert in public health and infectious disease control (FvdK), one epidemiologist (KM) and two physicians/PhD students in charge of the systematic literature research (MWH, LMOdB).

First, the expert committee defined search terms for the systematic literature review (see supplementary tables 1-5, available online only), which was conducted in MEDLINE in December 2009, in MEDLINE and EMBASE in November 2010 and abstracts from EULAR and American College of Rheumatology meetings in 2008/9. Relevant papers, among others found by searching references from keynote papers, were added by experts. Exclusion criteria were: non-rheumatic autoimmune diseases, malignancies, immunodeficiencies, transplantations, atopic diseases, animal studies, infections rather than vaccinations, vaccine development, phase I-III trials, in-vitro studies, non-English papers. Papers concerning the potential role of vaccinations in inducing rheumatic diseases were excluded, because these recommendations focus on the effect of vaccination on established disease. ${ }^{9-15}$

Experts independently graded literature on methodological quality and level of evidence. ${ }^{8}$ Each paper was evaluated by at least three experts. Abstracts were rated a level of evidence 3 or 4 . Data were extracted using predefined criteria. Results of studies on adult patients with rheumatic diseases were extrapolated to juvenile patients. Critical appraisal results were debated, and subsequently the recommendations were formulated. The strength of each recommendation was based on the level of evidence. ${ }^{8}$ Finally, a closed Delphi voting procedure was performed to determine the level of agreement with the recommendation ranging from 0 (no agreement) to 10 (maximal agreement). Recommendations on which the agreement was below 7.5 were removed.

\section{RESULTS}

Sixty papers were critically appraised on vaccination versus immunosuppressive drugs and 147 on vaccination versus rheumatic diseases after the first search (figure 1). In the second search (November 
2010), six of the included abstracts had come out as full text papers and three additional papers were found. Evidence on vaccinations versus immunosuppressive drugs (table 1) and versus rheumatic diseases (table 2) was summarised. The task force agreed on 15 recommendations, reaching a level of agreement of 7.9-9.8 (table 3).

Noteworthy was that antibody responses were taken as surrogate endpoints for efficacy in all studies; only three studies evaluated the occurrence of infections (pneumococcal, flu, varicella) after vaccination. ${ }^{16-18}$ Most studies were powered for immunogenicity analysis, not safety. Results on safety should be interpreted with caution.

\section{Medication use}

When indicated according to national guidelines, non-live vaccines can be administered to PaedRD patients using glucocorticosteroids, diseasemodifying antirheumatic drugs (DMARD) and/or anti-tumour necrosis factor alpha (TNF $\alpha)$ therapy.

Non-live composite vaccines administered to patients on glucocorticosteroids, DMARD or anti-TNF $\alpha$ treatment do not aggravate disease or cause serious adverse events in comparison with healthy subjects. For glucocorticosteroids this was shown for the hepatitis $B$ virus (HBV) vaccine, flu and pneumococcal polysaccharide vaccine (PPV). ${ }^{19-30}$ For methotrexate the safety of the flu and 23-valent PPV (PPV23) was shown in adult rheumatoid arthritis and systemic lupus erythematosus (SLE) patients. ${ }^{21}$ 2526 30-32 Data on DMARD other than methotrexate were scarce. ${ }^{19}$ 21-23 25-27 30 33-37 Non-live vaccines were safe in those studies, with similar disease activity following flu and PPV vaccination and no serious adverse events. ${ }^{21-2325} 273033$ Regarding biological agents, PPV23, the heptavalent pneumococcal conjugate vaccine (PCV7) and the flu vaccine were safe in patients on anti-TNF $\alpha$ treatment. ${ }^{16} 2128313238$ Data on other biological agents were too limited to make definite statements on safety.
In patients using rituximab, disease activity was similar before and after influenza vaccination and adverse events after flu, PPV23 and tetanus toxoid (TT) vaccination were comparable to healthy controls and patients without rituximab. ${ }^{39-41}$ Influenza vaccination in patients on tocilizumab (anti-interleukin 6) did not induce disease flares. ${ }^{36}$

It is recommended to determine pathogen-specific antibody concentrations after vaccination in $\mathrm{PaedRD}$ patients on high-dose glucocorticosteroids ( $\geq 2 \mathrm{mg} / \mathrm{kg}$ or a total dose of $\geq 20 \mathrm{mg} /$ day for 2 weeks or more) or on rituximab, and can be considered in patients on anti-TNF $\alpha$ treatment at the time of vaccination.

In contrast to the good serological responses while using low-dose glucocorticosteroids (in children $<0.5-2.0 \mathrm{mg} / \mathrm{kg}$ per day $^{25} 28$ or $<10 \mathrm{mg} /$ day $^{20} 212324262729$ in adults), three studies including adult patients on glucocorticosteroids greater than $10 \mathrm{mg} /$ day showed reduced responses to influenza vaccination. ${ }^{19} 2230$

Rituximab blunted the immune response to TT and flu vaccines when administered 1 month after treatment. ${ }^{35}$ 39-43 When these vaccinations were administered 6-10 months after rituximab, immune responses were adequate ${ }^{39} 40$ to reduced. ${ }^{44}$ Similarly, the immune response to PPV23 administered 6-7 months after rituximab treatment was reduced. ${ }^{39-41} 4344$

Anti-TNF $\alpha$ treatment did not reduce the percentage of patients reaching protective antibody concentrations after TT,

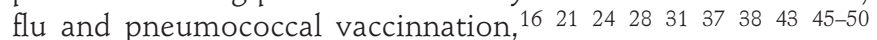
although some studies found lower geometric mean antibody concentrations (GMC). ${ }^{31} 5152$ Thirty-one juvenile idiopathic arthritis (JIA) patients on anti-TNF $\alpha$ treatment had similar protection rates after PCV7 as patients without anti-TNF $\alpha$. However, GMC to three serotypes were lower. ${ }^{16}$ Reduced responses were also described in 10 spondylarthropathy patients on anti-TNF $\alpha$ therapy. ${ }^{53}$ Measuring pathogen-specific antibodies can be considered in patients on anti-TNF $\alpha$ therapy.

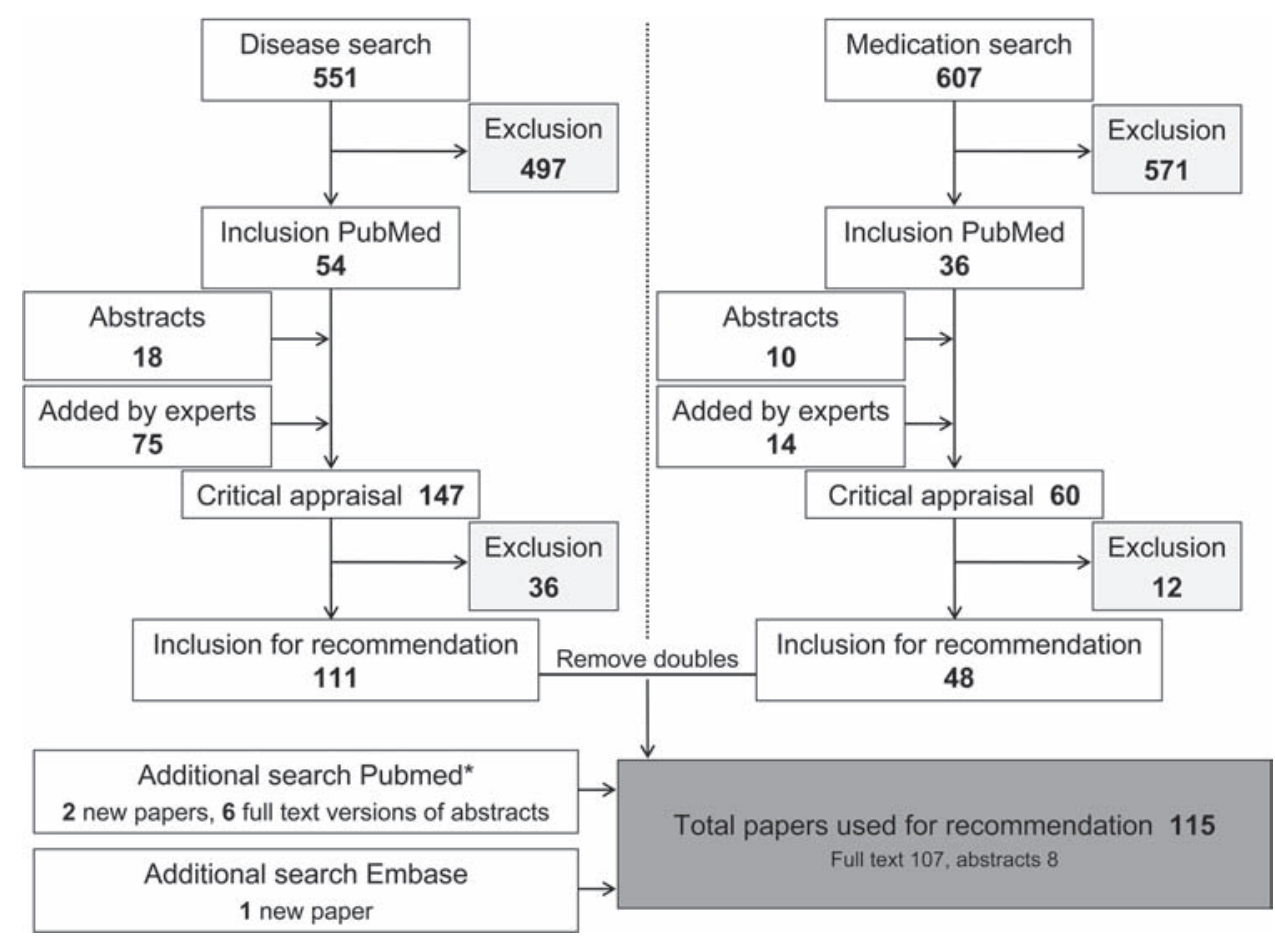

Figure 1 Search strategy for the systematic literature review. Two searches were performed, (A) one for vaccinations in combination with paediatric auto-inflammatory or rheumatic diseases and (B) one for vaccinations in combination with immunosuppressive drugs. ${ }^{*}$ An additional search was performed in PubMed and EMBASE in November 2010 using the same search string to obtain additional recently published papers. 
Table 1 Immunosuppressive drugs vs immunogenicity and safety of vaccination

\begin{tabular}{|c|c|c|c|c|c|}
\hline Medication & Studies (abstract) & $\begin{array}{l}\text { Patients (juvenile)/ } \\
\text { healthy controls }\end{array}$ & LoE & Immunogenicity (LoE) & Safety (LoE) \\
\hline Methotrexate & & & & $\begin{array}{l}\text { Lower response to PPV23 on methotrexate } \\
13-25 \mathrm{mg} / \text { week }(2 \mathrm{~A}) \text {, trend to lower } \\
\text { response to VZV on methotrexate } \\
12-25 \mathrm{mg} / \mathrm{m}^{2} / \text { week (3) }\end{array}$ & $\begin{array}{l}\text { Live vaccines (VZV, MMR booster, } \\
\text { YFV booster) safe in } 135 \text { patients on } \\
\text { methotrexate }<15 \mathrm{mg} / \mathrm{m}^{2} / \text { week (3) }\end{array}$ \\
\hline Other DMARD & $10(1)$ & $627(49) / 231$ & 1B-4 & $\begin{array}{l}\text { Good immunogenicity PPV on AZA and } \\
\text { CFM (3) }\end{array}$ & $\begin{array}{l}\text { Composite vaccines safe in } 210 \\
\text { patients (1B) }\end{array}$ \\
\hline \multirow[t]{2}{*}{ Rituximab } & $6(1)$ & $313(0) / 70$ & 1B-4 & $\begin{array}{l}\text { Good immunogenicity TT } 6 \text { months after } \\
\text { rituximab (1B) }\end{array}$ & $\begin{array}{l}\text { Composite vaccines safe in } 133 \\
\text { patients (1B) }\end{array}$ \\
\hline & & & & Lower response to flu (2A), PPV23 (1B) & $\begin{array}{l}\text { YFV booster vaccine safe in } 3 \\
\text { patients (4) }\end{array}$ \\
\hline Anti-IL-6 & $2(2)$ & $98(31) / 19$ & 3 & Good immunogenicity flu (3) & $\begin{array}{l}\text { Composite vaccines safe in } 31 \\
\text { patients (3) }\end{array}$ \\
\hline \multirow[t]{2}{*}{ Anti-CD11a } & $1(0)$ & $62(0) / 0$ & $1 \mathrm{~B}$ & $\begin{array}{l}\text { Good immunogenicity PPV23 compared to } \\
\text { placebo in } 62 \text { psoriasis patients (1B) }\end{array}$ & NA \\
\hline & & & & $\begin{array}{l}\text { Lower TT-specific antibodies, but similar } \\
\text { protection rate in } 62 \text { psoriasis patients (1B) }\end{array}$ & \\
\hline
\end{tabular}

\footnotetext{
*Only three papers studied paediatric patients, in these studies the maximum GC dose was $10 \mathrm{mg} /$ day or dosages below $0.5-2 \mathrm{mg} / \mathrm{kg}$ per day.
}

AZA, azathioprine; CFM, cyclophosphamide; DMARD, disease-modifying antirheumatic drugs; GC, glucocorticosteroids; HBV, hepatitis B virus vaccine; HCQ, hydroxychloroquine; LoE, level of evidence; MMR, measles, mumps, rubella vaccine; NA, not applicable; PCV7, 7-valent pneumococcal conjugate vaccine; PPV23, 23-valent pneumococcal polysaccharide vaccine; TNF, tumour necrosis factor; TT, tetanus toxoid vaccine; YFV, yellow fever vaccine.

Data were too limited to construct recommendations on the measurement of antibody concentrations in patients on newer biological agents. ${ }^{36} 375455$

In PaedRD patients with an indication for pneumococcal or influenza vaccination, it is recommended to vaccinate before rituximab use whenever possible.

Rituximab impairs the immune response until 6 months after treatment. $^{35}$ 39-41 4344 In eight rheumatoid arthritis patients receiving flu and PPV23 vaccination 6 days before initiating rituximab treatment, responses were comparable to patients without rituximab, ${ }^{44}$ suggesting that immunisations should be given before rituximab treatment whenever possible.

In PaedRD patients with a contaminated wound, it is suggested to administer tetanus immunoglobulin to patients treated with rituximab in the past 6 months, because responses to TT vaccination can be reduced.

Responses to TT vaccination are reduced in the first month after rituximab treatment, whereas responses 6 months after rituximab treatment are adequate. The immune response in the period between the first and sixth month after rituximab treatment is currently unknown. ${ }^{39} 42$ As responses to TT vaccination may be reduced, the committee suggests administering tetanus immunoglobulin in patients with a contaminated wound that have been treated with rituximab in the past 6 months.

It is recommended to determine pneumococcal serotype-specific antibody concentrations after PPV23 vaccination in PaedRD patients on methotrexate at the time of vaccination.
The immunogenicity of vaccines has predominantly been tested in adult patients on standard dose methotrexate of $15 \mathrm{mg} /$ week. Responses to vaccines were sufficient in patients using methotrexate, except for the PPV23 vaccination, and possibly for other polysaccharide vaccines. Protection rates were comparable with patients without methotrexate or healthy controls after HBV (one study), flu (five studies) and TT vaccination (one study). ${ }^{21} 24-26304546$ In contrast, in all seven studies including the T-cell-independent PPV, lower responses were found in patients treated with methotrexate $15 \mathrm{mg} /$ week, or in a minority with 15-25 mg/week. 24324850525657 The effect of synthetic DMARD other than methotrexate on antibody responses is unknown, because results of studies were contradictory. ${ }^{19} 21-232527 \quad 3033 \quad 34$ In those patients, determining pneumococcal serotype-specific antibody concentrations after PPV23 vaccination can be considered. If responses are insufficient, the conjugate vaccine can be considered, because this vaccine may be more immunogenic in immunocompromised patients. ${ }^{58}$

\section{Live-attenuated vaccines}

It is recommended to withhold live-attenuated vaccines in PaedRD patients on high-dose DMARD, high-dose glucocorticosteroids or biological agents. However, vaccination can be considered on a case-to-case basis weighing the risk of infections versus the hypothetical risks of vaccination.

According to the manufacturer's statement, live-attenuated vaccines should not be administered to immunosuppressed patients, given the risk of inducing infection by vaccination. 
Table 2 Immunogenicity and safety of vaccinations in PaedRD

\begin{tabular}{lllll}
\hline Vaccine & Studies (abstract) & $\begin{array}{l}\text { Patients (juvenile)/ } \\
\text { healthy controls }\end{array}$ & LoE & Immunogenicity (LoE) \\
\hline BCG* $^{10(0)}$ & $16124(16063) / 65$ & $2 B-4$ & $\begin{array}{l}\text { Lower responses to PPD in 115 JIA } \\
\text { patients and 20 SLE patients several } \\
\text { years after BCG (2B) }\end{array}$ & $\begin{array}{l}\text { Lafety (LoE) } \\
\text { Kawasaki disease patients (3) }\end{array}$
\end{tabular}

HAV/HBV $\quad 9(2) \quad 432(49) / 56 \quad 2 B-3 \quad$ Good immunogenicity HAV in 10 patients

(3) and HBV in 344 patients (2B)Lower responses HBV in 44 RA patients (3), and in $40 \mathrm{SpA}$ patients on anti-TNF $\alpha(3)$

$\begin{array}{lrll}\text { Hib } & 2(0) & 85(0) / 0 & 3 \\ \text { HPV } & 1(1) & 22(22) / 0 & 4 \\ \text { Flu } & 41(4) & 2551(131) / 901 & 1 B-3\end{array}$

Good immunogenicity in 85 patients (3)

Flu $\quad 41(4)$

$2551(131) / 901$

$1 B-3$

NA

Good immunogenicity in 1035 patients (1B-3)Good immunogenicity, but lower GMC or lower responses to 1 strain in 408 patients (1B-3)Lower responses on immunosuppressive drugs in 760 patients (1B-3)Lower responses in 206 patients (1B-2B)

\begin{tabular}{|c|c|c|c|c|}
\hline Meningococcal & $1(0)$ & $234(234) / 0$ & 3 & $\begin{array}{l}\text { Good immunogenicity in } 234 \text { patients } \\
\text { (NeisVac-C), despite lower GMC in patients } \\
\text { on immunosuppressive drugs (3) }\end{array}$ \\
\hline $\mathrm{MMR}^{*}$ & $7(0)$ & $321(229) / 22$ & $2 \mathrm{~B}-3$ & Good immunogenicity in 98 patients (3) \\
\hline
\end{tabular}

$\begin{array}{llll}\text { Pneumococcal } & 23(1) & 1889(63) / 142 & 1 B-3\end{array}$

-3 Good immunogenicity PPV in 557 patients (2A) and PCV7 in 63 JIA patients, including 31 on anti-TNF $\alpha$ (2B)Lower responses to PPV in 311 patients (2B), 20 patients on anti-TNF $\alpha(2 A)$ and to PCV7 in 10 patients on anti-TNF $\alpha(3)$

\begin{tabular}{|c|c|c|c|c|}
\hline Polio* & $1(0)$ & $115(0) / 0$ & 3 & NA \\
\hline TDaP/TD/TT & $10(1)$ & $501(138) / 156$ & $2 \mathrm{~B}-3$ & $\begin{array}{l}\text { Good immunogenicity TT in } 316 \text { patients, } \\
\text { also } 6 \text { months after rituximab, and on } \\
\text { anti-TNF } \alpha(2 B) \text { Good immunogenicity TD } \\
\text { in } 34 \text { patients ( } 3 \text { )Good immunogenicity TT, } \\
\text { but lower GMC in } 92 \text { patients ( } 3 \text { ) and in } 41 \\
\text { patients on anti-CD11a (2B)Poor responders } \\
\text { to TT among } 29 \text { SLE patients (3) }\end{array}$ \\
\hline Travellers' vaccines $^{\dagger}$ & $1(0)$ & $1(0) / 0$ & 4 & NA \\
\hline VZV* & $3(1)$ & $86(30) / 47$ & $2 \mathrm{~B}-3$ & $\begin{array}{l}\text { Good immunogenicity to zoster in } 55 \\
\text { patients (3)Responses within range of } \\
\text { controls in } 25 \text { patients, but trend towards } \\
\text { lower response (2B)Five of } 6 \text { IBD patients } \\
\text { had positive immunity (4) }\end{array}$ \\
\hline YFV* & $2(0)$ & $91(0) / 15$ & $2 \mathrm{~B}-3$ & $\begin{array}{l}\text { Trend to lower GMC, } 1 \text { non-responder } \\
\text { of } 17 \text { patients on anti-TNF } \alpha \text { and } \\
\text { methotrexate (2B) }\end{array}$ \\
\hline
\end{tabular}

HAV safe; no worsening of disease in 10 patients (3) HBV safe; similar disease activity as non-vaccinated patients in 44 patients (2B), no worsening of disease in 77 patients (3), no severe AE in 293 patients (3)

Safe; no worsening of disease in 85 patients (3)

Safe; no serious AE in 22 patients (4) Safe; similar disease activity as nonvaccinated patients in 429 patients (1B-2B), no worsening of disease in 871 patients (3), similar AE as $\mathrm{HC}$ in 177 patients (2B)

Safe; no worsening of disease in 234 patients (NeisVac-C) (3)

Safe; no worsening of disease in 222 patients (3)Case reports of flares of JIA and ITP (4)

PPV safe; similar disease activity as nonvaccinated patients in 117 patients (1B), no worsening of disease in 157 patients (3), similar AE as HC in 131 patients (3), no serious $A E$ in 40 patients (3)PCV safe; no worsening of disease, no severe $A E$ in 63 JIA patients (3)

Four flares after IPV/OPV vaccination in 73 SLE patients vs no flares in 37 SLE controls (3)

TT safe; no worsening of disease in 113 patients, no severe $A E$ in 103 patients (3)

Transverse myelitis reported 3 months after rabies vaccination (4)

Safe; no worsening of disease in 86 patients (3-4), no serious $A E$ in 31 patients (3-4), similar $\mathrm{AE}$ as $\mathrm{HC}$ in 55 patients (3)VZV-like rash in $20 \%$ of patients (4)

Safe; similar AE as $\mathrm{HC}$ in 91 patients (3)

*Live-attenuated vaccines, both non-live as live-attenuated OPV are available.

${ }^{\dagger}$ Cholera, Japanese encephalitis, rabies, tickborne encephalitis (FSME), typhoid fever.

$A E$, adverse events; $B C G$, bacillus Calmette-Guérin; GMC, geometric mean antibody concentrations; HAV, hepatitis A virus vaccine; HBV, hepatitis $B$ virus vaccine; $H C$, healthy controls; Hib, Haemophilus influenzae type B vaccine; HPV, human papillomavirus vaccine; IBD, inflammatory bowel disease; IPV, inactivated poliovirus; ITP, idiopathic thrombocytopenic purpura; JIA, juvenile idiopathic arthritis; LoE, level of evidence; MMR, measles, mumps, rubella vaccine; NA, not applicable; NeisVac-C, meningococcal serogroup C conjugate vaccine; $\mathrm{OPV}$, oral poliovirus vaccines; PaedRD, paediatric patients with rheumatic diseases; PCV7, 7-valent pneumococcal conjugate vaccine; PPD, purified protein derivative of tuberculin; PPV, pneumococcal polysaccharide vaccine; RA, rheumatoid arthritis; SLE, systemic lupus erythematosus; SpA, spondylarthropathy patients; TD, tetanus-diphtheria vaccine; TDaP, tetanus-diphtheria-acellular pertussis vaccines; TNF, tumour necrosis factor; TT, tetanus toxoid vaccine; VZV, varicella zoster virus vaccine;

YFV, yellow fever virus vaccines.

The immunosuppressive effect of DMARD or glucocorticosteroids depends on the dosage and duration of use. Current cut-off values for high dosages differ and are predominantly based on consensus. ${ }^{6} 59$ The committee has defined high DMARD dosages as intravenous pulse therapy or dosages higher than the standard dosages (methotrexate $15 \mathrm{mg} / \mathrm{m}^{2}$ per week, cyclosporine $2.5 \mathrm{mg} /$ $\mathrm{kg}$ per day, sulphasalazine $40 \mathrm{mg} / \mathrm{kg}$ per day up to $2 \mathrm{~g} /$ day, azathioprine $1-3 \mathrm{mg} / \mathrm{kg}$, cyclophosphamide $0.5-2.0 \mathrm{mg} / \mathrm{kg}$ per day orally, leflunomide $0.25-0.5 \mathrm{mg} / \mathrm{kg}$ per day, 6-mercaptopurine $1.5 \mathrm{mg} / \mathrm{kg}$ per day). ${ }^{60-62}$ For glucocorticosteroids, $2 \mathrm{mg} / \mathrm{kg}$ or greater or a total of $20 \mathrm{mg} /$ day or more during 2 weeks or more is considered a high dose. ${ }^{659}$ Noteworthy is that a chronically administered glucocorticosteroid dose of $20 \mathrm{mg} /$ day is equivalent to dosages below $2 \mathrm{mg} /$ $\mathrm{kg}$ per day in children. In these patients less than $2 \mathrm{mg} / \mathrm{kg}$ per day are also considered high dosages.

Available studies on live-attenuated vaccines usually include patients on low-dose DMARD or glucocorticosteroids, and the available evidence on safety is reassuring. The measles, mumps, rubella (MMR) booster and yellow fever virus (YFV) booster were safe in patients on methotrexate less than $15 \mathrm{mg} / \mathrm{m}^{2}$ per 
Table 3 Recommendations with grade of recommendation and Delphi score on agreement among experts

\begin{tabular}{|c|c|c|c|}
\hline RC & & Grade & $\begin{array}{l}\text { Delphi score } \\
\text { (mean (SD)) }\end{array}$ \\
\hline 1 & $\begin{array}{l}\text { When indicated according to national guidelines*, non-live vaccines can be administered to PaedRD using glucocorticosteroids, } \\
\text { DMARDs and/or anti-TNF } \alpha \text { therapy. }\end{array}$ & C & $9.8(0.4)$ \\
\hline 2 & $\begin{array}{l}\text { To assure adequate immune responses, it is recommended to determine pathogen-specific antibody concentrations after vaccination in } \\
\text { all PaedRD on high-dose glucocorticosteroids }{ }^{\dagger}(\geq 2 \mathrm{mg} / \mathrm{kg} \text { or } \geq 20 \mathrm{mg} / \text { day for } \geq 2 \text { weeks) or on rituximab. Measuring pathogen-specific } \\
\text { antibody concentrations can be considered in patients on anti-TNF } \alpha \text { treatment. }\end{array}$ & C & $8.4(2.9)$ \\
\hline 3 & $\begin{array}{l}\text { In patients with an indication for pneumococcal or influenza vaccination, it is recommended to vaccinate prior to rituximab use whenever } \\
\text { possible. }\end{array}$ & C & $9.8(0.6)$ \\
\hline \multirow[t]{2}{*}{5} & $\begin{array}{l}\text { To assure adequate immune responses, it is recommended to determine pneumococcal strain-specific antibody concentrations after the } \\
\text { PPV23 in PaedRD on methotrexate at time of vaccination. }\end{array}$ & C & $7.9(3.4)$ \\
\hline & LIVE-ATTENUATED VACCINES & & \\
\hline 6 & $\begin{array}{l}\text { Until more data are available, it is recommended to withhold live-attenuated vaccines in patients on high-dose DMARD, }{ }^{\dagger} \text { high-dose } \\
\text { glucocorticosteroids }{ }^{\dagger} \text { or biological agents. However, vaccination can be considered on a case-to-case basis weighing the risk of infections } \\
\text { vs the hypothetical risk of inducing infections by vaccination. }\end{array}$ & $\mathrm{D}$ & $9.2(0.9)$ \\
\hline \multirow[t]{2}{*}{9} & $\begin{array}{l}\text { It is recommended to assess VZV infection and vaccination history in PaedRD, especially in those patients anticipating high-dose } \\
\text { immunosuppressive therapy } y^{\dagger} \text { or biologicals. In case of a negative history for VZV infection or vaccination, VZV vaccine should be } \\
\text { considered, ideally before initiation of immunosuppressive therapy. }{ }^{\ddagger}\end{array}$ & $\mathrm{D}$ & $9.2(1.2)$ \\
\hline & NON-LIVE VACCINES & & \\
\hline 10 & The TT vaccine should be administered to patients with juvenile SLE and JIA according to the national vaccination guidelines. & B & $9.8(0.6)$ \\
\hline 11 & $\begin{array}{l}\text { It is recommended to adhere to national vaccination guidelines* for vaccination against hepatitis B virus, tetanus, diphtheria, pertussis, } \\
\text { Hib, pneumococci and meningococci in PaedRD. }\end{array}$ & C & $9.8(0.6)$ \\
\hline 12 & $\begin{array}{l}\text { It is recommended to adhere to national vaccination guidelines* for vaccination against hepatitis A virus, poliovirus, Japanese encephalitis, } \\
\text { typhoid fever, rabies, cholera or tickborne encephalitis in PaedRD. }\end{array}$ & D & $8.9(1.8)$ \\
\hline 13 & Annual influenza vaccination should be considered in all PaedRD. & D & $8.4(2.2)$ \\
\hline 14 & $\begin{array}{l}\text { In the case vaccinations against Hib, pneumococci and meningococci are not included in the national vaccination programmes }{ }^{*} \text {, these } \\
\text { vaccinations are recommended for PaedRD with low complement levels or functional asplenia. These vaccinations can be considered in } \\
\text { patients on high-dose immunosuppressive drugs }{ }^{\dagger} \text { or biological agents before therapy. }{ }^{\ddagger}\end{array}$ & $\mathrm{D}$ & $9.3(1.6)$ \\
\hline
\end{tabular}

\begin{abstract}
*National vaccination guidelines worldwide can be found on http://apps.who.int/immunization monitoring/en/globalsummary/scheduleselect.cfm.
${ }^{\dagger}$ High-dose DMARD are defined as intravenous pulse therapy, cyclosporine $>2.5 \mathrm{mg} / \mathrm{kg}$ per day, sulphasalazine $>40 \mathrm{mg} / \mathrm{kg}$ per day or $2 \mathrm{~g} / \mathrm{day}$, azathioprine $>3 \mathrm{mg} / \mathrm{kg}$, cyclophosphamide orally $>2.0 \mathrm{mg} / \mathrm{kg}$ per day, leflunomide $>0.5 \mathrm{mg} / \mathrm{kg}$ per day, or 6-mercaptopurine $>1.5 \mathrm{mg} / \mathrm{kg}$ per day. High-dose glucocorticosteroids are dosages $\geq 2 \mathrm{mg} / \mathrm{kg}$ or $\geq 20 \mathrm{mg} /$ day for 2 weeks or more. In patients chronically treated with $20 \mathrm{mg} /$ day glucocorticosteroids, dosages below $2 \mathrm{mg} / \mathrm{kg}$ per day are also considered high dosages. ${ }^{\ddagger}$ Generally 2-4 weeks is recommended before immunosuppressive therapy is commenced.

BCG, bacillus Calmette-Guérin; DMARD, disease-modifying antirheumatic drugs; Hib, Haemophilus influenzae type B; HPV, human papillomavirus; JIA, juvenile idiopathic arthritis; MMR, measles, mumps, rubella; PaedRD, paediatric patients with rheumatic diseases; PPV23, 23-valent pneumococcal polysaccharide; RC, recommendation; SLE, systemic lupus erythematosus; TNF, tumour necrosis factor; TT, tetanus toxoid; VZV, varicella zoster virus; YFV, yellow fever virus.
\end{abstract}

week ( $\mathrm{n}=118)$, various DMARD (sulphasalazine, leflunomide, cyclosporine, cyclophosphamide), anti-TNF $\alpha(n=28)$ and rituximab $(n=3) .{ }^{35} 63-65$ Similarly, primary varicella zoster virus (VZV) vaccination did not induce severe adverse events or disease flares in 25 PaedRD patients on glucocorticosteroids, methotrexate, and/or various DMARD. ${ }^{17}$ Data on patients on high-dose glucocorticosteroids, high-dose DMARD or biological agents are scarce. Therefore, the committee considers it prudent to withhold these vaccines in such patients until more data are available.

It is recommended to adhere to national vaccination guidelines for live-attenuated vaccines in PaedRD patients unless patients are on high-dose DMARD, high-dose glucocorticosteroids or biological agents. Booster vaccinations against VZV, MMR and yellow fever can be considered in patients on methotrexate less than $15 \mathrm{mg} / \mathrm{m} / \mathrm{per}$ week or lowdose glucocorticosteroids.

MMR and VZV vaccinations can be given safely and efficaciously when PaedRD patients are not immunosuppressed as a result of treatment. In addition, evidence supports the safety of VZV, MMR and YFV booster vaccines in patients on methotrexate less than $15 \mathrm{mg} / \mathrm{m}^{2}$ per week or low-dose glucocorticosteroids. ${ }^{17}$ 63-65
In contrast to one case report of a flare systemic JIA after rubella vaccination, larger studies failed to find this association. ${ }^{66}$ In two studies including 15 and 207 JIA patients, respectively, MMR booster vaccination did not increase disease activity, not even when using regular methotrexate dosages and low-dose glucocorticosteroids. ${ }^{6364} \mathrm{MMR}$ booster showed good immunogenicity in 10 JIA patients, irrespective of regular methotrexate dosages and etanercept. ${ }^{63}$

More studies are required before recommendations on primary vaccinations with live-attenuated vaccines can be made. The primary VZV vaccination was studied in 25 PaedRD patients, of whom all were on methotrexate treatment (mean dose $16.4 \mathrm{mg} / \mathrm{m}^{2}$ per week) and 13 patients were on glucocorticosteroids (0.1-0.7 mg/kg per day). The response rate was $50 \%$ in patients versus $72 \%$ in 18 healthy controls. No severe adverse events, generalised varicella infection, herpes zoster or worsening of disease activity were reported. ${ }^{17}$ Adequate immunogenicity was found in 28 patients with SLE and six with inflammatory bowel disease after VZV booster vaccination. ${ }^{67} 68$

No severe adverse events were seen after YFV booster in 91 adult patients with rheumatic disease on various amounts of immunosuppressive drugs, including 26 patients on biological 
agents. ${ }^{35} 65$ Effects on disease activity are unknown. The immunogenicity of YFV booster vaccination was good, although responses were reduced in patients on TNF $\alpha$ blocking agents. ${ }^{65}$

The risk of contracting tuberculosis is increased in patients treated with immunosuppressive drugs, especially TNF $\alpha$ blocking agents. ${ }^{69-78}$ Bacillus Calmette-Guérin (BCG) vaccination should be administered before initiating immunosuppressive drugs. ${ }^{79} 80$ The safety of BCG vaccination has not been studied. Regarding efficacy, reduced induration sizes to the tuberculin skin test were found in 115 JIA and 20 SLE patients on low-dose immunosuppressive drugs. ${ }^{81} 82$

It is recommended to withhold BCG vaccination during active Kawasaki disease.

This recommendation is supported by literature describing local inflammation at the BCG vaccination site in $37-50 \%$ of 15805 Kawasaki patients. ${ }^{83-88}$

It is recommended to assess VZV infection and vaccination history in PaedRD patients, especially in those patients anticipating high-dose immunosuppressive therapy or biological agents. In case of a negative history for VZV infection or vaccination, VZV vaccine should be considered, ideally beforethe initiation of immunosuppressive therapy.

Case reports exist of severe disseminated primary VZV infections or zoster infections in patients on anti-TNF $\alpha$ therapy or methotrexate. ${ }^{89-91} \mathrm{VZV}$ vaccination has been proved beneficial in immunocompromised juvenile leukaemia patients and HIV patients. ${ }^{92} 93$ Based on the above, we suggest assessing VZV infection or vaccination status in all PaedRD patients, especially in those anticipating immunosuppressive treatment or biological agents. In case of a negative or inconclusive history for chickenpox or VZV vaccination, VZV vaccine should be considered, ideally before the initiation of immunosuppressive therapy or biological agents. Current consensus-based guidelines recommend to wait at least 2-4 weeks before starting treatment. $^{692}$

\section{Non-live composite vaccines}

It is recommended to adhere to national vaccination guidelines for vaccination against cholera, diphtheria, Haemophilus influenzae type $B$ (Hib), hepatitis A virus (HAV), HBV, Japanese encephalitis, pertussis, pneumococci, poliovirus and meningococci, rabies, tetanus, tickborne encephalitis and typhoid fever, in PaedRD patients.

Based on the evidence supporting the safety and immunogenicity of non-live composite vaccines, the committee recommends adhering to national vaccination programmes. Evidence strongly supported the safety and immunogenicity of TT vaccination in juvenile SLE and JIA patients, even when using immunosuppressive drugs. ${ }^{45} 9495$ Most studies supported the safety and immunogenicity of diphtheria, ${ }^{95} \mathrm{Hib},{ }^{96} 97 \mathrm{HAV},{ }^{98} \mathrm{HBV},{ }^{26} 53$ 98-102 PPV, 27 515254 103-106 pneumococcal conjugate ${ }^{16} 53$ and meningococcal conjugate vaccines. ${ }^{107}$ Four SLE flares were described after polio vaccination in a retrospective analysis. ${ }^{10}$ Well-controlled prospective studies were not available. Data for vaccination against cholera, Japanese encephalitis, tickborne encephalitis and typhoid fever were lacking. ${ }^{108}$

Annual influenza vaccination should be considered in all PaedRD patients

General recommendations state that children that are 'immunosuppressed' should receive annual inactivated influenza vaccinations. ' As 'immunosuppressed' is not further specified, the question arises as to whether PaedRD patients are at higher risk of (complications of) flu infection. Two large retrospective studies showed an increased risk of flu in older patients with rheumatic diseases and a beneficial effect of vaccination on admission for pneumonia/flu or death. ${ }^{109} 110$

Seasonal influenza vaccination was safe and immunogenic in adult and PaedRD patients. ${ }^{19-25}$ 28-31 3334 36-38 404147 111-121 Vaccination reduced the occurrence of viral respiratory and bacterial infections after vaccination. ${ }^{18}$ Based on the possible increased risk of (complicated) flu infections and the safety and immunogenicity of non-live flu vaccines, annual influenza vaccination can be considered in all PaedRD patients.

If vaccinations against Hib, pneumococci and meningococci are not included in the national vaccination programmes, these vaccinations are recommended for PaedRD patients with low complement levels or functional asplenia. These vaccinations can be considered in patients on high-dose immunosuppressive drugs or biological agents before therapy.

Patients with complement deficiencies or functional asplenia, such as some SLE ${ }^{122}$ and polyarticular JIA ${ }^{123} 124$ patients, are at increased risk of acquiring Hib, meningococcal and pneumococcal infections. ${ }^{122}$ Vaccinations against these pathogens are recommended when pathogen-specific antibody concentrations are insufficient.

It is recommended to adhere to national vaccination guidelines for vaccination against human papillomavirus (HPV) in PaedRD patients. Given the higher risk of HPV infection in female SLE patients, these patients should be advised to be vaccinated in adolescence. However, physicians should be vigilant for potential thromboembolic events.

Preliminary results showed no serious adverse events after HPV vaccination (gardasil) in 22 JIA and seronegative inflammatory arthritis patients. ${ }^{125}$

SLE patients may have a higher risk of persistent HPV infections than healthy subjects, with a higher risk of squamous intraepithelial lesions and cervical cancer. ${ }^{126-128}$ These data underline the necessity of protection against HPV infection in juvenile SLE patients before they become sexually active. Noteworthy is that venous thromboembolic events were reported after Gardasil vaccination. ${ }^{129}$ Although it is uncertain whether these thromboembolic events can be attributed to HPV vaccination, vigilance after HPV vaccination in SLE patients seems warranted. 130131

\section{DISCUSSION}

Safe and effective vaccination is crucial in PaedRD patients given the increased risks of infections. ${ }^{2-5}$ The EULAR task force formulated 15 recommendations on vaccination in PaedRD patients. As evidence was lacking for numerous vaccines, diseases and immunosuppressive drugs, most recommendations have strength $\mathrm{C}$ or $\mathrm{D}$.

The recommendations refer to national vaccination guidelines, as these take into consideration local epidemiology, programmatic issues, resources and policies. Worldwide, these guidelines differ considerably (http://apps.who.int/immunization_monitoring/en/globalsummary/scheduleselect.cfm). Vaccinations against Hib, pneumococci and meningococci, HPV and VZV are not uniformly included in national guidelines, but are considered important in the management of PaedRD patients. For these vaccines, specific recommendations were made.

Generally, the immunogenicity of vaccines is good in PaedRD patients. There are some exceptions, depending on the type and dose of immunosuppressive treatment and the type of vaccine. Methotrexate reduced responses to T-cell-independent PPV, whereas T-cell-dependent responses to conjugate and live-attenuated vaccines were good. Responses to various vaccines (flu, VZV) were reduced in patients on high-dose 
glucocorticosteroids or azathioprine. Anti-TNF $\alpha$ did not reduce the immunogenicity of vaccines according to most controlled studies. Rituximab reduced responses to both T-cell-independent and $\mathrm{T}$-cell-dependent vaccines. Offering vaccination before immunosuppressive drugs or determining antibodies may be considered in these patients. Notably, the effect of immunosuppressive drugs or disease on the persistence of antibodies after vaccination is still unknown. In addition, the effect of vaccination on the infection rate should be assessed.

Regarding safety, both disease activity and adverse events were studied. Importantly, most studies were underpowered to assess safety. Sufficiently powered safety studies are warranted. Nonetheless, non-live vaccines seem to be safe while using glucocorticosteroids (2.5-40 mg/day), methotrexate 7-25 mg/ week, other DMARD such as azathioprine, or biological agents. Limited data so far indicate that live-attenuated booster vaccines are safe in patients on regular methotrexate dosages, low-dose glucocorticosteroids and anti-TNF $\alpha$ therapy. Although it is sensible to withhold live-attenuated vaccines in patients on high-dose immunosuppressive drugs and biological agents, these vaccines, especially booster vaccinations, are not contraindicated as such. Primary vaccines are generally administered before the onset of rheumatic diseases, and booster vaccines may be administered when essential.

Finally, these recommendations need to be updated regularly, because new evidence will become available on vaccinating PaedRD patients on immunomodulating drugs.

Funding This study was funded by EULAR.

\section{Competing interests None.}

Contributors MWH and NMW: outline and conduct of study, literature search, appraisal and analysis of evidence, writing paper. LMOdB: literature search, appraisal and analysis of evidence, writing paper. All other authors: appraisal and analysis of evidence, review of paper

Provenance and peer review Not commissioned; externally peer reviewed.

Author affiliations 'Department of Paediatric Immunology, Wilhelmina Children's Hospital, University Medical Centre Utrecht, Utrecht, The Netherlands

${ }^{2}$ Department of Rheumatology and Clinical Immunology, University Medical Centre Groningen, University of Groningen, Groningen, The Netherlands

${ }^{3}$ Vaccine Evaluation Unit, Health Protection Agency North West, Manchester Royal Infirmary, Manchester, UK

${ }^{4}$ Inflammation Sciences Research Group, School of Translational Medicine, University of Manchester, Manchester, UK

${ }^{5}$ Centre for Infectious Disease Control Netherlands, National Institute of Public Health and the Environment (RIVM), Bilthoven, The Netherlands

${ }^{6}$ Department of Paediatrics, Paediatric Rheumatology, CeReMAI, CHU de Bicêtre, University of Paris SUD, Le Kremlin Bicêtre, France

${ }^{7}$ Department of Paediatrics, University of Gothenburg, Göteborg, Sweden

${ }^{8}$ German Rheumatism Research Centre Berlin, Epidemiology Unit, Children's University Hospital Charité Berlin, Berlin, Germany

${ }^{9}$ Department of Paediatrics, Pediatria II-Reumatologia, Istituto G Gaslini, University of Genova, Genova, Italy

${ }^{10}$ Department of Paediatric Immunology, Newcastle upon Tyne Hospitals NHS

Foundation Trust, Newcastle upon Tyne, UK

${ }^{11}$ Department of Paediatrics, Immunology and Rheumatology Unit, School of Medicine of Ribeirão Preto, University of São Paulo, São Paulo, Brazil

${ }^{12}$ Department of Paediatrics, Municipal Hospital St Georg Leipzig, Academic Teaching Hospital of the University of Leipzig, Leipzig, Germany

\section{REFERENCES}

1. Ada G. Vaccines and vaccination. N Engl J Med 2001;345:1042-53

2. Doran MF, Crowson CS, Pond GR, et al. Frequency of infection in patients with rheumatoid arthritis compared with controls: a population-based study. Arthritis Rheum 2002;46:2287-93.

3. Fessler BJ. Infectious diseases in systemic lupus erythematosus: risk factors, management and prophylaxis. Best Pract Res Clin Rheumatol 2002;16:281-91.

4. Silva CAA, Terreri MTRA, Barbosa CMPL, et al. Immunization consensus for children and adolescents with rheumatic diseases. Bras J Rheumatol 2009; 49:562-89
5. Bongartz T, Sutton AJ, Sweeting MJ, et al. Anti-TNF antibody therapy in rheumatoid arthritis and the risk of serious infections and malignancies: systematic review and meta-analysis of rare harmful effects in randomized controlled trials. JAMA 2006; 295:2275-85.

6. BSR Clinical Affairs Committee. Vaccinations in the Immunocompromised Person: Guidelines for the Patient Taking Immunosuppressants, Steroids and the New Biologic Therapies. London: British Society for Rheumatology, 2002.

7. Kroger AT, Atkinson WL, Marcuse EK, et al. General recommendations on immunization: recommendations of the Advisory Committee on Immunization Practices (ACIP). MMWR Recomm Rep 2006;55:1-48.

8. Dougados M, Betteridge N, Burmester GR, et al. EULAR standardised operating procedures for the elaboration, evaluation, dissemination, and implementation of recommendations endorsed by the EULAR standing committees. Ann Rheum Dis 2004;63:1172-6.

9. Offit PA, Hackett CJ. Addressing parents' concerns: do vaccines cause allergic or autoimmune diseases? Pediatrics 2003;111:653-9.

10. Schattner A. Consequence or coincidence? The occurrence, pathogenesis and significance of autoimmune manifestations after viral vaccines. Vaccine 2005:23:3876-86.

11. Chen RT, Pless R, Destefano F. Epidemiology of autoimmune reactions induced by vaccination. J Autoimmun 2001;16:309-18.

12. Molina V, Shoenfeld Y. Infection, vaccines and other environmental triggers of autoimmunity. Autoimmunity 2005;38:235-45.

13. Update: vaccine side effects, adverse reactions, contraindications, and precautions Recommendations of the Advisory Committee on Immunization Practices (ACIP). MMWR Recomm Rep 1996;45:1-35

14. Shoenfeld $\mathbf{Y}$, Aron-Maor A. Vaccination and autoimmunity - 'vaccinosis': a dangerous liaison? J Autoimmun 2000;14:1-10.

15. Wraith DC, Goldman M, Lambert PH. Vaccination and autoimmune disease: what is the evidence? Lancet 2003;362:1659-66.

16. Farmaki E, Kanakoudi-Tsakalidou F, Spoulou V, et al. The effect of antiTNF treatment on the immunogenicity and safety of the 7-valent conjugate pneumococcal vaccine in children with juvenile idiopathic arthritis. Vaccine 2010;28:5109-13.

17. Pileggi GS, de Souza CB, Ferriani VP. Safety and immunogenicity of varicella vaccine in patients with juvenile rheumatic diseases receiving methotrexate and corticosteroids. Arthritis Care Res (Hoboken) 2010;62:1034-9.

18. Stojanovich L. Influenza vaccination of patients with systemic lupus erythematosus (SLE) and rheumatoid arthritis (RA). Clin Dev Immunol 2006;13:373-5

19. Abu-Shakra M, Press J, Varsano N, et al. Specific antibody response after influenza immunization in systemic lupus erythematosus. J Rheumatol 2002;29:2555-7.

20. Chalmers A, Scheifele D, Patterson C, et al. Immunization of patients with rheumatoid arthritis against influenza: a study of vaccine safety and immunogenicity. J Rheumatol 1994;21:1203-6.

21. Fomin I, Caspi D, Levy V, et al. Vaccination against influenza in rheumatoid arthritis: the effect of disease modifying drugs, including TNF alpha blockers. Ann Rheum Dis 2006:65:191-4.

22. Holvast A, Huckriede A, Wilschut J, et al. Safety and efficacy of influenza vaccination in systemic lupus erythematosus patients with quiescent disease. Ann Rheum Dis 2006;65:913-18.

23. Holvast A, van Assen S, de Haan A, et al. Studies of cell-mediated immune responses to influenza vaccination in systemic lupus erythematosus. Arthritis Rheum 2009;60:2438-47

24. Kaine JL, Kivitz AJ, Birbara C, et al. Immune responses following administration of influenza and pneumococcal vaccines to patients with rheumatoid arthritis receiving adalimumab. J Rheumatol 2007;34:272-9.

25. Kanakoudi-Tsakalidou F, Trachana M, Pratsidou-Gertsi P, et al. Influenza vaccination in children with chronic rheumatic diseases and long-term immunosuppressive therapy. Clin Exp Rheumatol 2001;19:589-94.

26. Kasapçopur 0, Cullu F, Kamburoglu-Goksel A, et al. Hepatitis B vaccination in children with juvenile idiopathic arthritis. Ann Rheum Dis 2004;63:1128-30.

27. Lipnick RN, Karsh J, Stahl NI, et al. Pneumococcal immunization in patients with systemic lupus erythematosus treated with immunosuppressives. J Rheumatol 1985;12:1118-21

28. Lu Y, Jacobson DL, Ashworth $L A$, et al. Immune response to influenza vaccine in children with inflammatory bowel disease. Am J Gastroenterol 2009;104:444-53.

29. Malleson PN, Tekano JL, Scheifele DW, et al. Influenza immunization in children with chronic arthritis: a prospective study. J Rheumatol 1993;20:1769-73.

30. Wallin L, Quintilio W, Locatelli $F$, et al. Safety and efficiency of influenza vaccination in systemic lupus erythematosus patients. Acta Reumatol Port 2009;34:498-502.

31. Gelinck LB, van der Bijl AE, Beyer WE, et al. The effect of anti-tumour necrosis factor alpha treatment on the antibody response to influenza vaccination. Ann Rheum Dis 2008;67:713-16.

32. Gelinck LB, van der Bijl AE, Visser LG, et al. Synergistic immunosuppressive effect of anti-TNF combined with methotrexate on antibody responses to the 23 valent pneumococcal polysaccharide vaccine. Vaccine 2008;26:3528-33. 
33. Wiesik-Szewczyk E, Romanowska M, Mielnik P, et al. Anti-influenza vaccination in systemic lupus erythematosus patients: an analysis of specific humoral response and vaccination safety. Clin Rheumatol 2010;29:605-13.

34. Denman EJ, Denman AM, Greenwood BM, et al. Failure of cytotoxic drugs to suppress immune responses of patients with rheumatoid arthritis. Ann Rheum Dis 1970;29:220-31.

35. Mota LMH, Oliveira AC, Lima RAC, et al. Yellow fever vaccination in patients with rheumatic diseases in use of immunosuppressive drugs - occurrence of adverse events (abstract). Ann Rheum Dis 2009;68(Suppl 3):319.

36. Shinoki T, Kikuchi M, Kaneko U, et al. Safety and response to influenza vaccine in patients with juvenile rheumatoid arthritis receiving tosilizumab. Arthritis Rheum 2008;58:(Suppl 9):1495

37. Tsuru T, Suzaki M, Yoshio N, et al. Immune response to influenza vaccine in patients during the treatment with tocilizumab - comparison with conventional DMARDS and TNF inhibitors (abstract). Ann Rheum Dis 2008;67(Suppl 2):339

38. Mamula P, Markowitz JE, Piccoli DA, et al. Immune response to influenza vaccine in pediatric patients with inflammatory bowel disease. Clin Gastroenterol Hepatol 2007;5:851-6.

39. Bingham C0, 3rd, Looney RJ, Deodhar A, et al. Immunization responses in rheumatoid arthritis patients treated with rituximab: results from a controlled clinica trial. Arthritis Rheum 2010:62:64-74.

40. van Assen S, Holvast A, Benne CA, et al. Humoral responses after influenza vaccination are severely reduced in patients with rheumatoid arthritis treated with rituximab. Arthritis Rheum 2010;62:75-81.

41. Oren S, Mandelboim M, Braun-Moscovici Y, et al. Vaccination against influenza in patients with rheumatoid arthritis: the effect of rituximab on the humoral response. Ann Rheum Dis 2008;67:937-41.

42. van der Kolk LE, Baars JW, Prins MH, et al. Rituximab treatment results in impaired secondary humoral immune responsiveness. Blood 2002;100:2257-9.

43. Gelinck LB, Teng YK, Rimmelzwaan GF, et al. Poor serological responses upon influenza vaccination in patients with rheumatoid arthritis treated with rituximab. Ann Rheum Dis 2007:66:1402-3.

44. Rehnberg M, Brisslert M, Amu S, et al. Vaccination response to protein and carbohydrate antigens in patients with rheumatoid arthritis after rituximab treatment. Arthritis Res Ther 2010;12:R111.

45. Kamdar A, Giclas PC, Myones BL. Immunologic responsiveness in patients with JIA on methotrexate and etanercept: candida skin test and tetanus vaccination (abstract). Arthritis Rheum 2009;60(Suppl 10):227.

46. Kapetanovic MC, Saxne T, Nilsson JA, et al. Influenza vaccination as model for testing immune modulation induced by anti-TNF and methotrexate therapy in rheumatoid arthritis patients. Rheumatology (Oxford) 2007:46:608-11.

47. Kubota T, Nii T, Nanki T, et al. Anti-tumor necrosis factor therapy does not diminish the immune response to influenza vaccine in Japanese patients with rheumatoid arthritis. Mod Rheumatol 2007;17:531-3.

48. Mease PJ, Ritchlin CT, Martin RW, et al. Pneumococcal vaccine response in psoriatic arthritis patients during treatment with etanercept. J Rheumatol 2004;31:1356-61.

49. Nii T, Kubota T, Nanki T, et al. Reevaluation of antibody titers 1 year after influenza vaccination in patients with rheumatoid arthritis receiving TNF blockers. Mod Rheumatol 2009;19:216-18.

50. Visvanathan S, Keenan GF, Baker DG, et al. Response to pneumococcal vaccine in patients with early rheumatoid arthritis receiving infliximab plus methotrexate or methotrexate alone. J Rheumato/ 2007;34:952-7

51. Melmed GY, Agarwal N, Frenck RW, et al. Immunosuppression impairs response to pneumococcal polysaccharide vaccination in patients with inflammatory bowel disease. Am J Gastroenterol 2010:105:148-54.

52. Kapetanovic MC, Saxne T, Sjöholm A, et al. Influence of methotrexate, TNF blockers and prednisolone on antibody responses to pneumococcal polysaccharide vaccine in patients with rheumatoid arthritis. Rheumatology (Oxford) 2006:45:106-11.

53. Salinas FG, De Rycke L, Cantaert T, et al. TNF blockade impairs T cell dependent antibody responses (abstract). Ann Rheum Dis 2009;68(Suppl 3):238.

54. Krueger JG, Ochs HD, Patel P, et al. Effect of therapeutic integrin (CD11a) blockade with efalizumab on immune responses to model antigens in humans: results of a randomized, single blind study. J Invest Dermatol 2008;128:2615-24.

55. Tay L, Leon F, Vratsanos G, et al. Vaccination response to tetanus toxoid and 23-valent pneumococcal vaccines following administration of a single dose of abatacept: a randomized, open-label, parallel group study in healthy subjects. Arthritis Res Ther 2007;9:R38.

56. McInnes I, Kavanaugh A, Krueger GG, et al. Golimumab, a new human TNF-alpha antibody, administered every 4 weeks as a subcutaneous injection in psoriatic arthritis: response to pneumococcal vaccine in the randomized, placebo-controlled, Go-Reveal Study (abstract). Ann Rheum Dis 2008;67(Suppl 2):529.

57. O'dell JR, Gilg J, Palmer W, et al. Pneumococcal vaccine in rheumatoid arthritis. J Clin Rheumatol 1996;2:59-63.

58. Advisory Committee on Immunization Practices. Preventing pneumococcal disease among infants and young children. Recommendations of the Advisory Committee on Immunization Practices (ACIP). MMWR Recomm Rep 2000:49:1-35.
59. Recommendations of the Advisory Committee on Immunization Practices (ACIP): use of vaccines and immune globulins for persons with altered immunocompetence. MMWR Recomm Rep 1993:42:1-18.

60. Hashkes PJ, Laxer RM. Medical treatment of juvenile idiopathic arthritis. JAMA 2005:294:1671-84.

61. Murray KJ, Lovell DJ. Advanced therapy for juvenile arthritis. Best Pract Res Clin Rheumatol 2002;16:361-78.

62. Silverman $\mathbf{E}$, Mouy R, Spiegel L, et al. Leflunomide or methotrexate for juvenile rheumatoid arthritis. N Engl J Med 2005;352:1655-66.

63. Borte S, Liebert UG, Borte $\mathrm{M}$, et al. Efficacy of measles, mumps and rubella revaccination in children with juvenile idiopathic arthritis treated with methotrexate and etanercept. Rheumatology (Oxford) 2009:48:144-8.

64. Heijstek MW, Pileggi GC, Zonneveld-Huijssoon E, et al. Safety of measles, mumps and rubella vaccination in juvenile idiopathic arthritis. Ann Rheum Dis 2007:66:1384-7.

65. Scheinberg M, Guedes-Barbosa LS, Mangueira C, et al. Yellow fever revaccination during infliximab therapy. Arthritis Care Res (Hoboken) 2010;62:896-8.

66. Korematsu S, Miyahara H, Kawano T, et al. A relapse of systemic type juvenile idiopathic arthritis after a rubella vaccination in a patient during a long-term remission period. Vaccine 2009;27:5041-2

67. Barbosa CMP, Terreri MT, Len CA, et al. Varicella vaccine in children and adolescents with systemic lupus erythematosus (SLE) - immunogenicity and safety [abstract]. Arthritis Rheum 2009:60(Suppl 10):1521.

68. Lu Y, Bousvaros A. Varicella vaccination in children with inflammatory bowel disease receiving immunosuppressive therapy. J Pediatr Gastroenterol Nutr 2010;50:562-5

69. Atzeni F, Bendtzen K, Bobbio-Pallavicini F, et al. Infections and treatment of patients with rheumatic diseases. Clin Exp Rheumatol 2008;26(1 Suppl 48):S67-73.

70. Askling J, Fored CM, Brandt L, et al. Risk and case characteristics of tuberculosis in rheumatoid arthritis associated with tumor necrosis factor antagonists in Sweden. Arthritis Rheum 2005;52:1986-92

71. Brassard P, Lowe AM, Bernatsky S, et al. Rheumatoid arthritis, its treatments, and the risk of tuberculosis in Quebec, Canada. Arthritis Rheum 2009;61:300-4.

72. Brassard P, Kezouh A, Suissa S. Antirheumatic drugs and the risk of tuberculosis. Clin Infect Dis 2006;43:717-22

73. Gómez-Reino JJ, Carmona L, Valverde VR, et al. Treatment of rheumatoid arthritis with tumor necrosis factor inhibitors may predispose to significant increase in tuberculosis risk: a multicenter active-surveillance report. Arthritis Rheum 2003:48:2122-7

74. Kim HA, Yoo CD, Baek HJ, et al. Mycobacterium tuberculosis infection in a corticosteroid-treated rheumatic disease patient population. Clin Exp Rheumatol 1998;16:9-13

75. Sayarlioglu M, Inanc M, Kamali S, et al. Tuberculosis in Turkish patients with systemic lupus erythematosus: increased frequency of extrapulmonary localization. Lupus 2004:13:274-8

76. Seong SS, Choi CB, Woo JH, et al. Incidence of tuberculosis in Korean patients with rheumatoid arthritis (RA): effects of RA itself and of tumor necrosis factor blockers. J Rheumatol 2007;34:706-11.

77. Tam LS, Leung CC, Ying SK, et al. Risk of tuberculosis in patients with rheumatoid arthritis in Hong Kong - the role of TNF blockers in an area of high tuberculosis burden. Clin Exp Rheumatol 2010;28:679-85

78. Tam LS, Li EK, Wong SM, et al. Risk factors and clinical features for tuberculosis among patients with systemic lupus erythematosus in Hong Kong. Scand J Rheumato/ 2002:31:296-300.

79. Lovell DJ, Reiff A, llowite NT, et al. Safety and efficacy of up to eight years of continuous etanercept therapy in patients with juvenile rheumatoid arthritis. Arthritis Rheum 2008;58:1496-504.

80. Ruperto N, Lovell DJ, Quartier P, et al. Long-term safety and efficacy of abatacept in children with juvenile idiopathic arthritis. Arthritis Rheum 2010;62:1792-802.

81. Abe T, Homma M. Immunological reactivity in patients with systemic lupus erythematosus. Humoral antibody and cellular immune responses. Acta Rheumatol Scand 1971;17:35-46.

82. Kiray $\mathbf{E}$, Kasapcopur O, Bas V, et al. Purified protein derivative response in juvenile idiopathic arthritis. J Rheumatol 2009;36:2029-32

83. Weinstein M. Inflammation at a previous inoculation site: an unusual presentation of Kawasaki disease. Can Med Assoc J 2006;174:459-60.

84. Uehara R, Igarashi $\mathrm{H}$, Yashiro $\mathrm{M}$, et al. Kawasaki disease patients with redness or crust formation at the Bacille Calmette-Guérin inoculation site. Pediatr Infect Dis J 2010;29:430-3.

85. Kuniyuki S, Asada M. An ulcerated lesion at the BCG vaccination site during the course of Kawasaki disease. J Am Acad Dermatol 1997;37:303-4.

86. Hsu YH, Wang YH, Hsu WY, et al. Kawasaki disease characterized by erythema and induration at the Bacillus Calmette-Guérin and purified protein derivative inoculation sites. Pediatr Infect Dis J 1987:6:576-8.

87. Chalmers D, Corban JG, Moore PP. BCG site inflammation: a useful diagnostic sign in incomplete Kawasaki disease. J Paediatr Child Health 2008:44:525-6.

88. Antony D, Jessy PL. Involvement of BCG scar in Kawasaki disease. Indian Pediatr 2005;42:83-4 
89. Kinder AJ, Hassell AB, Brand J, et al. The treatment of inflammatory arthritis with methotrexate in clinical practice: treatment duration and incidence of adverse drug reactions. Rheumatology (Oxford) 2005;44:61-6.

90. Strangfeld A, Listing J, Herzer P, et al. Risk of herpes zoster in patients with rheumatoid arthritis treated with anti-TNF-alpha agents. JAMA 2009:301:737-44.

91. Vonkeman H, ten Napel C, Rasker $\mathrm{H}$, et al. Disseminated primary varicella infection during infliximab treatment. J Rheumatol 2004;31:2517-18.

92. Marin M, Güris D, Chaves SS, et al. Prevention of varicella: recommendations of the Advisory Committee on Immunization Practices (ACIP). MMWR Recomm Rep 2007:56:1-40.

93. LaRussa P, Steinberg S, Gershon AA. Varicella vaccine for immunocompromised children: results of collaborative studies in the United States and Canada. J Infect Dis 1996;174(Suppl 3):S320-3.

94. Kashef S, Ghazizadeh F, Derakhshan A, et al. Antigen-specific antibody response in juvenile-onset SLE patients following routine immunization with tetanus toxoid. Iran J Immunol 2008:5:181-4.

95. Höyeraal HM, Mellbye OJ. Humoral immunity in juvenille rheumatoid arthritis. Ann Rheum Dis 1974;33:248-54

96. Battafarano DF, Battafarano NJ, Larsen L, et al. Antigen-specific antibody responses in lupus patients following immunization. Arthritis Rheum 1998;41:1828-34.

97. Mercado U. Why have rheumatologists been reluctant to vaccinate patients with systemic lupus erythematosus? J Rheumatol 2006;33:1469-71

98. Beran J, Dedek P, Stepánová V, et al. Safety and immunogenicity of a combined vaccine against hepatitis $A$ and $B$ in patients with autoimmune hepatitis. Cent Eur J Public Health 2005:13:20-3.

99. Cruz BA, Laurindo IMM, Bertolo MB, et al. A. Efficacy and safety of vaccination in rheumatoid arthritis patients treated with methotrexate: a systematic literature research (abstract). Ann Rheum Dis 2009;68(Suppl 3):412

100. Elkayam 0, Yaron M, Caspi D. Safety and efficacy of vaccination against hepatitis B in patients with rheumatoid arthritis. Ann Rheum Dis 2002;61:623-5.

101. Erkek $\mathbf{E}$, Ayaslioglu $E$, Erkek AB, et al. Response to vaccination against hepatitis $B$ in patients with Behcet's disease. J Gastroenterol Hepatol 2005;20:1508-11.

102. Kuruma KA, Borba EF, Lopes MH, et al. Safety and efficacy of hepatitis B vaccine in systemic lupus erythematosus. Lupus 2007;16:350-4.

103. Croft SM, Schiffman G, Snyder E, et al. Specific antibody response after in vivo antigenic stimulation in systemic lupus erythematosus. J Rheumatol 1984:11:141-6.

104. Elkayam 0, Caspi D, Reitblatt T, et al. The effect of tumor necrosis factor blockade on the response to pneumococcal vaccination in patients with rheumatoid arthritis and ankylosing spondylitis. Semin Arthritis Rheum 2004;33:283-8.

105. Klippel JH, Karsh J, Stahl NI, et al. A controlled study of pneumococcal polysaccharide vaccine in systemic lupus erythematosus. Arthritis Rheum 1979;22:1321-5

106. Mercado U, Acosta H, Diaz-Molina R. Antibody response to pneumococcal polysaccharide vaccine in systemic sclerosis. J Rheumatol 2009;36:1549-50.

107. Zonneveld-Huijssoon E, Ronaghy A, Van Rossum MA, et al. Safety and efficacy of meningococcal $\mathrm{C}$ vaccination in juvenile idiopathic arthritis. Arthritis Rheum 2007:56:639-46.

108. Bir LS, Esmeli FO, Cenikli U, et al. Acute transverse myelitis at the conus medullaris level after rabies vaccination in a patient with Behçet's disease. J Spinal Cord Med 2007:30:294-6.

109. Hak $\mathbf{E}$, Nordin J, Wei F, et al. Influence of high-risk medical conditions on the effectiveness of influenza vaccination among elderly members of 3 large managedcare organizations. Clin Infect Dis 2002;35:370-7.

110. Nichol KL. Complications of influenza and benefits of vaccination. Vaccine 1999;17(Suppl 1):S47-52
111. Ogimi C, Tanaka R, Saitoh A, et al. Immunogenicity of influenza vaccine in children with pediatric rheumatic diseases receiving immunosuppressive agents. Pediatr Infect Dis J 2011:30:208-11.

112. Del Porto $\mathbf{F}$, Laganà $B$, Biselli $R$, et al. Influenza vaccine administration in patients with systemic lupus erythematosus and rheumatoid arthritis. Safety and immunogenicity. Vaccine 2006;24:3217-23.

113. Elkayam 0, Bashkin A, Mandelboim M, et al. The effect of infliximab and timing of vaccination on the humoral response to influenza vaccination in patients with rheumatoid arthritis and ankylosing spondylitis. Semin Arthritis Rheum 2010:39:442-7.

114. Herron A, Dettleff G, Hixon B, et al. Influenza vaccination in patients with rheumatic diseases. Safety and efficacy. JAMA 1979;242:53-6.

115. Louie JS, Nies KM, Shoji KT, et al. Clinical and antibody responses after influenza immunization in systemic lupus erythematosus. Ann Intern Med 1978:88:790-2.

116. Mercado U, Acosta H, Avendaño L. Influenza vaccination of patients with systemic lupus erythematosus. Rev Invest Clin 2004;56:16-20.

117. Pons VG, Reinertsen JL, Steinberg AD, et al. Decreased cell-mediated cytotoxicity against virus-infected cells in systemic lupus erythematosus. J Med Virol 1979;4:15-23.

118. Ristow SC, Douglas RG, Jr, Condemi JJ. Influenza vaccination of patients with systemic lupus erythematosus. Ann Intern Med 1978:88:786-9.

119. Setti M, Fenoglio D, Ansaldi F, et al. Influenza vaccination with a virosomal vaccine does not affect clinical course and immunological parameters in scleroderma patients. Vaccine 2009;27:3367-72

120. Williams GW, Steinberg AD, Reinertsen JL, et al. Influenza immunization in systemic lupus eruthematosus. A double-blind trial. Ann Intern Med 1978;88:729-34.

121. Zycinska K, Romanowska M, Nowak I, et al. Antibody response to inactivated subunit influenza vaccine in patients with Wegener's granulomatosis. J Physiol Pharmacol 2007;58(Suppl 5):819-28.

122. Millet A, Decaux 0 , Perlat A, et al. Systemic lupus erythematosus and vaccination. Eur J Intern Med 2009:20:236-41.

123. Gilliam BE, Wolff AE, Moore TL. Partial C4 deficiency in juvenile idiopathic arthritis patients. J Clin Rheumatol 2007:13:256-60.

124. Vicario JL, Martinez-Laso J, Gomez-Reino JJ, et al. Both HLA class II and class III DNA polymorphisms are linked to juvenile rheumatoid arthritis susceptibility. Clin Immunol Immunopathol 1990;56:22-8.

125. Singer NG, Wallette M, Tomanova-Soltys I, et al. Interim safety data of Gardasil in a trial in females with JIA and seronegative arthritis (abstract). Arthritis Rheum 2009;60(Suppl 10):226.

126. Klumb EM, Araújo ML, Jr , Jesus GR, et al. Is higher prevalence of cervical intraepithelial neoplasia in women with lupus due to immunosuppression? $J$ Clin Rheumatol 2010;16:153-7.

127. Nath R, Mant C, Luxton J, et al. High risk of human papillomavirus type 16 infection and of development of cervical squamous intraepithelial lesions in systemic lupus erythematosus patients. Arthritis Rheum 2007;57:619-25.

128. Tam LS, Chan AY, Chan PK, et al. Increased prevalence of squamous intraepithelial lesions in systemic lupus erythematosus: association with human papillomavirus infection. Arthritis Rheum 2004;50:3619-25.

129. Slade BA, Leidel L, Vellozzi C, et al. Postlicensure safety surveillance for quadrivalent human papillomavirus recombinant vaccine. JAMA 2009;302:750-7

130. Petri M. Update on anti-phospholipid antibodies in SLE: the Hopkins' Lupus Cohort. Lupus 2010;19:419-23.

131. Schmugge M, Revel-Vilk S, Hiraki L, et al. Thrombocytopenia and thromboembolism in pediatric systemic lupus erythematosus. J Pediatr 2003;143:666-9. 